\title{
Halka Açı Olmayan Anonim Şirketlerde Sistematik Risk Ölçütü Beta Katsayısının Tahmin Edilmesi: Turizm Sektörü Uygulaması
}

Yusuf TEPELI $\dot{I}^{*}$

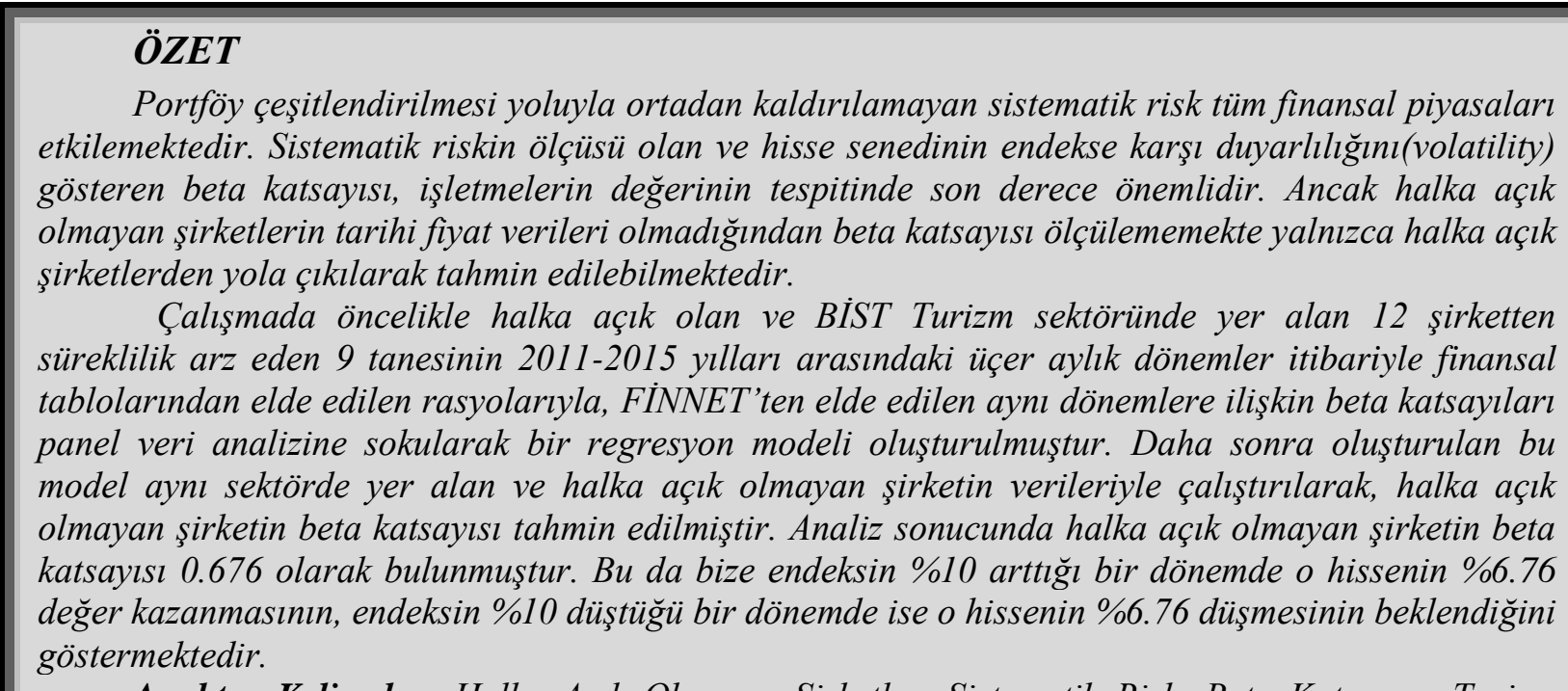

Anahtar Kelimeler: Halka Açık Olmayan Şirketler, Sistematik Risk, Beta Katsayısı, Turizm Sektörü.

JEL Sinıflandırması: G12, G32, M41.
\end{abstract}

\section{The Prediction of Beta Coefficient as a Systematic Risk Measure in the Non-Public} Joint Stock Companies: An Application in Tourism Sector

\section{ABSTRACT}

Systematic risk that can not be removed from the portfolio through portfolio diversification affects all financial markets. The beta coefficient, which is a systematic risk measure and indicates stock volatility, is extremely important in determining the value of businesses. However, since the nonpublic companies do not have historical price data, they can not estimate the beta coefficient but can only be estimated from publicly traded companies.

In the study, first quarterly financial statements between the years of 2011-2015 of 9 out of 12 publicly held companies that are located in the BIST Tourism sector and the beta coefficients of the same periods obtained from FINNET are inserted into the panel data analysis and a regression model created. Later on, this model was run with data from a company in the same sector that is not open to the public, and the beta coefficient of the non-public company was estimated. As a result of the analysis, the beta coefficient of the non-public company was found to be 0.676. This suggests that when the index is increased by 10\%, that share gains 6.76\%, and when the index drops by $10 \%$, that share is expected to fall by $6.76 \%$.

Keywords: Non-public companies, Systematic Risk, Beta Coefficient, Tourism Sector, Panel Data Analysis.

Jel Classification: G12, G32, M41.

\footnotetext{
${ }^{*}$ Arş. Gör. Yusuf TEPELİ, Muğla Sıtkı Koçman Üniversitesi, İktisadi ve İdari Bilimler Fakültesi, yusuftepeli@mu.edu.tr.
} 


\section{GİRiş}

Halka açık şirketler için piyasada oluşan fiyat bilgileri mevcut olduğundan, sistematik risk ölçütü beta katsayısının tahmin edilmesi kolaydır. Bu katsayının hesaplanmasında, hisse senedi getirilerinin bağımlı değişken, piyasa getirisinin ise bağımsız değişken olarak alındığı, zaman serileri regresyon modelleri kullanılmaktadır. Bu modellerde kullanılan veriler, ilgili hisse senetlerine ait tarihi veriler olup, senedin işlem gördüğü menkul kıymet piyasasından elde edilebilmektedir. Ancak, menkul kıymet piyasasında işlem görmeyen menkul kıymetlerin beta katsayıları, belirtilen regresyon modelleri kullanılarak hesaplanamamaktadır (Ercan vd., 2007: 296).

Halka açık olmayan şirketlerin sistematik riskinin tahmin edilmesi de yatırımcılar açısından en az halka açık şirketler kadar önemlidir. Örneğin, halka açık olmayan bir firmanın ilk halka arzı (Initial Public Offering "IPO”) veya borsada işlem görmeyen şirketlerin satın alma ya da birleşme işlemlerinde betanın bilinmesi yatırım kararının daha gerçekçi irdelenmesini sağlayacaktır ( Ersoy vd., 2010:49). Ancak halka açık olmayan şirketlerde piyasa verileri mevcut olmadığından, beta katsayısının tespit edilmesi kolay olmayıp; muhasebe betaları (accounting betas), temel verilerden hareketle (fundamental betas) ve karşılaştırılabilir benzer şirket betaları yoluyla (Kırl1, 2006:124) "kaldıraçlı betalar" (Ercan, 2007:300) yoluyla olmak üzere muhasebe temelli değişkenler yardımıyla beta katsayısı tahmin edilebilmektedir.

$\mathrm{Bu}$ çerçevede, çalışmanın temel amacını, hisse senetleri BİST'de işlem gören turizm sektörü firmalarının beta katsayıları ile mali tablolarından elde edilen değişkenler arasındaki ilişkinin regresyon modeli ile tespiti ve bu modelin halka açı olmayan turizm sektöründeki işletme üzerinde uygulanabilirliği oluşturmaktadır. Bu amaçla yapılan çalışmada öncelikle halka açık olmayan firmalarda beta katsayısının hesaplanmasında kullanılan yöntemler incelenmiş, konuyla ilgili literatür taraması yapıldıktan sonra son olarak hisse senetleri BİST'te işlem gören turizm sektörü firmalarının 2011-2015 dönemine ait bilançolarından ve gelir tablolarından elde edilen veriler ile BIST'ten temin edilen beta verileri panel veri analizine tutulmakta ve elde edilen bulgularla borsada işlem görmeyen turizm sektöründeki, benzer büyüklükteki firmanın sistematik riski tahmin edilmektedir.

\section{HALKA AÇIK OLMAYAN IŞLETMELERDE BETA KATSAYISININ TAHMIN EDILMESI}

Sistematik riskin ölçütü olan beta katsayısı hesaplanırken, hisse senedi getirilerinin bağımlı, piyasa getirisinin ise bağımsız değişken olduğu zaman serileri regresyon modelleri kullanılmaktadır (Ercan, 2007: 296). Modelde kullanılan veriler ise, hisse senedinin işlem gördüğü menkul kıymet piyasasından elde edilebilmektedir. Ancak halka açık olmayan şirketlerin piyasada hisse senedi fiyatları mevcut olmadığından, bu şirketlerin beta katsayılarının tahmin edilmesinde zorluklar yaşanmaktadır. Bunun nedeni yukarıda belirtilen bağımlı ve bağımsız değişkene ait verilerin bulunmamasıdır. 
$\mathrm{Bu}$ çerçevede, halka açık olmayan yani borsada işlem görmeyen şirketlerin betalarının, halka açık şirketlerden farklı olarak muhasebe betaları, temel betalar ve karşılaştırılabilir, benzer şirket betaları yoluyla tahmin edilebilmektedir.

\subsection{Muhasebe Betaları Yoluyla Beta Katsayısının Tahmin Edilmesi}

Piyasa riski parametrelerinin tahmin edilmesinde başvurulan yöntemlerden bir tanesi, beta katsayısını hesaplamada hisse senedi fiyatlarıın değil muhasebe getirilerinin (kar değişkeninin) kullanılmasıdır. Bu çerçevede, beta katsayısı belirli bir dönemde firmanın genelinin ya da bir alt biriminin karlılığında meydana gelen değişimler ile piyasanın genelinde meydana gelen karlılık değişimleri arasında ilişki kurularak hesaplanabilmektedir (Ercan, 2007:301). Bu yöntem kullanılarak hesaplanan betalar "muhasebe betaları" olarak adlandırılmaktadır.

Muhasebe betalarının tahmin edilmesinde halka açık olmayan firmaların karlarında meydana gelen değişimlerle, BIST 100 (XU100) endeksi benzeri endekslerin getirilerinde meydana gelen değişimler ilişkilendirilerek, regresyon modelinin temel alındığı analizler yapılabilmektedir.

$\Delta$ Kar $_{\text {HalkaAaal lmayanimame }}=a+b \Delta$ Getiriler $r_{\text {BIST100 }}$

Yukarıdaki regresyon doğrusunun eğimi "b", firmanın muhasebe betasını ifade etmektedir. Eğer kazanç olarak şirketin faaliyet karı kullanıldıysa, regresyon ile bulunacak beta katsayısı kaldıraçsız beta, kazanç olarak net kar kullanıldıysa, bulunacak beta katsayısı kaldıraçlı beta olacaktır (Damodaran, 2002: 203).

Halka açık olmayan şirketler için sistematik risk ölçütü beta katsayısının tahmin edilmesinde, muhasebe yönteminin uygulanması ve muhasebe betasının tahmin edilmesi işleminde şu adımlar izlenmelidir (Kırlı, 2006: 124).

I. Halka açık olmayan şirketin mümkün olduğunca uzak geçmişten bugüne dayanan muhasebe kazanç verilerinin elde edilir. Bu verilerin yüzdelik artış veya azalışlarla ifade edilir.

II. Birinci adımda verilerin elde edildiği dönem itibariyle hisse senedi endeksi getirilerin yüzdelik artış veya azalışlarla hesaplanır.

III. Birinci adımda elde edilen verilerin bağımlı değişken ve ikinci adımda elde edilen verilerin ise bağımsız değiş̧ken olduğu basit regresyon modeli kurulur ve bu basit regresyon modeli çalı̧̧̧ııılır.

IV. Son adımda ise bir önceki adımda kurulan ve çalıştırılan regresyon modelindeki regresyon doğrusunun eğimi yani muhasebe betası elde edilir.

Muhasebe betaları yardımıyla hesaplama yapılması, halka açık olmayan firmaların yılda yalnız bir kez kar hesaplaması nedeniyle modelin açıllama gücünün zayıflamasına ve kar rakamlarının çoğu zaman birtakım muhasebe düzeltmelerine maruz bırakılması da 
betaların hatalı bir şekilde hesaplanmasına neden olabilmektedir (Damodaran, 2002: 203). Ancak regresyon modeline dahil edilecek verilerin sayısının artırılması ve enflasyonun etkilerinden arındırılması modelin açıklama gücünü artıracaktır.

\subsection{Temel Betalar Yoluyla Beta Katsayısının Tahmin Edilmesi}

Temel betalar; finansal kaldıraç oranı, satışların değişkenliği, karlılığın değişkenliği, borç oranları, kar payı dağıtma oranı, aktiflerin büyüme oranı vb. temel risk değişkenleri kullanılarak hesaplanan beta katsayılarıdır (Rosenberg ve Guy, 1976:67). Halka açık şirketlerin beta katsayıları ile bu temel değişkenler çoklu regresyon analizine sokularak, bunlar arasındaki ilişkinin, değerlemesi yapılan halka açık olmayan şirketin temel değişkenleriyle beta katsayısı arasında bulunmaya çalışılan ilişkiyle benzer olduğu varsayımına dayanarak, halka açık olmayan şirket için beta katsayısı tahmin edilir (Kırlı, 2006:125).

Temel verilere dayanarak tahmin edilen betanın tahminine esas oluşturan çoklu regresyon modeli aşağıdaki gibi ifade edilebilir (Elton vd., 2014: 145).

$$
\beta=a_{0}+a_{1} X_{1}+a_{2} X_{2}+\ldots . a_{N} X_{N}+e
$$

$\mathrm{Bu}$ eşitlikte;

$\beta=$ Temel verilere dayanılarak tahmin edilen sistematik risk ölçüsünü,

$a_{0}=$ Çoklu regresyon modelinin sabit katsayısını,

$a_{1 \ldots N}=1$ 'den N'ye kadar bağımsız değişkenlerin kısmi regresyon katsayısını,

$X_{1 \ldots N}=1$ 'den N'ye kadar bağımsız değişkenleri (betayı tahmin etmeye yönelik seçilen temel verileri),

$e=$ Çoklu regresyon modelinin rassal değişkenini ifade etmektedir.

Beaver, Ketler ve Scholes (1970) çalışmalarında beta katsayısı ile firma temel verilerinden kar payı dağıtma oranı, şirket varlıklarının yıllık büyüme oranı, finansal kaldıraç derecesi, likidite oranı, aktif büyüklüğü, şirket kazançlarındaki değişkenlik ve muhasebe betasını incelemiş ve aşağıdaki sonuçlara ulaşmışlardır (Beaver vd., 1970: 660-680).

Kar payı dağıtma oranı ile beta katsayısı arasında negatif bir ilişki olduğu görülmüştür. Yani işletmenin kar dağıtım oranı arttıkça riskliliği azalacaktır.

Şirket varlıklarının yıllık büyüme oranı ile beta katsayısı arasında pozitif bir ilişki gözlemlenmiştir.

Şirketlerin finansal kaldıraç derecesi, şirket kazançlarının volatilitesini artırmaktadır. $\mathrm{Bu}$ da riski ve beta katsayısını yükseltmektedir.

Likidite oranı ile beta katsayısı arasında negatif bir ilişki vardır. Bunun işletmenin vadesi gelen borçlarını ödeme gücünün yüksek olmasından kaynaklandığını söyleyebiliriz. 
Aktif büyüklüğü yüksek olan şirketlerin, aktif büyüklüğü düşük olan şirketlere oranla daha az riskli olduğu görülmüştür.

Şirket kazançlarındaki volatilite arttıkça, söz konusu şirketin piyasadaki değişimlerle korelasyonu artmakta ve beta katsayısı da yüksek olmaktadır.

Damodaran ise sistematik risk ölçütü beta katsayısının temel olarak üç değişkenin etkisiyle belirlendiğini öne sürmüştür. Bunlar, şirketin faaliyet konusunu oluşturan işin özelliği, şirketin faaliyet kaldıracı ve şirketin finansal kaldıracıdır. Örneğin; mevsimsel iş yapan şirketler, diğer faktörler aynı olmak koşuluyla, mevsimsel iş yapmayan şirketlere oranla daha yüksek beta katsayısına sahiptir. Damodaran'ın çalışmasında otomobil ve inşaat sektöründeki şirketlerin beta katsayılarının, yiyecek ve sigara sektöründeki şirketlerin beta katsayısından daha yüksek olduğu ortaya çıkmıştır. Ayrıca diğer faktörler aynı olmak koşuluyla yüksek faaliyet derecesine sahip şirketlerin beta katsayılarının, düşük faaliyet derecesine sahip şirketlerin beta katsayılarından daha yüksek olacağını öne sürmüştür (Damodaran, 2002: 18). Bunun nedeni toplam maliyetler içerisindeki sabit maliyet oranının yüksek olmasının, şirketlerin faaliyet karlarında daha fazla değişkenlik yaratacağı düşüncesidir. Damodaran'a göre diğer faktörler aynı olmak koşuluyla daha yüksek borç/özkaynak oranına sahip şirketler, yani finansal kaldıracı yüksek olan şirketler, daha yüksek beta katsayısına sahiptir. Çünkü yüksek kaldıraç net gelirin varyansını artıracaktır (Damodaran, 2002: 20). Bu bakımdan Damodaran'ın yaklaşımının, Beaver, Ketler ve Scholes'ın yaklaşımıyla paralellik gösterdiği görülmektedir.

Tarihi verilere dayanarak tahmin edilen betanın piyasadaki hareketlere karşı, her bir hisse senedinin ayrı ayrı tepkisini ölçmesi, temel verilere dayanarak tahmin edilen betaya göre üstün yönü olarak görülse de, şirketin gerek toplam aktif büyüklüğündeki değişiklikleri gerekse de önemli şirket karakteristiklerindeki değişiklikleri, uzun bir dönem geçtikten sonra sistematik risk göstergesi olarak yansıtması zayıf yönü olarak görülmektedir. Çünkü şirketin temel verilerindeki önemli değişiklikler temel verilerden hareketle beta hesaplanırken hemen betaya yansitılmaktadır. Bununla birlikte temel verilere dayanarak tahmin edilen betanın, belirli bir temel değişken karşısında, betanın etkilenme derecesini, analize katılan tüm şirketler için sabit kabul etmesi ise temel verilerden hareketle tahmin edilen betanın zayıf bir yönü olarak görülmektedir (Kırlı, 2006: 127).

\subsection{Karşılaştırılabilir Benzer Şirket Yoluyla Beta Katsayısının Tahmin Edilmesi}

$\mathrm{Bu}$ yöntemde halka açı olmayan şirketin faaliyet gösterdiği sektörde halka açık olmayan şirketle faaliyet kaldıracı, finansal kaldıraç ve iş riski bakımından benzerlik gösteren halka açık şirketlerin beta katsayıları esas alınarak halka açık olmayan şirketin beta katsayısı tahmin edilmektedir (Kırlı, 2006: 130). Kaldıraçlı betalar adı da verilen bu yöntemde halka açık olmayan şirketin beta katsayısını tahmin edebilmek için aşağıdaki adımlar izlenir (Damodaran, PCV: 182). 
I. Firmanın değerliliğini etkileyen aynı ekonomik güçler tarafından etkilenen, tercihen aynı faaliyet dalında ancak daha genel, halka açık karşılaştırılabilir firmalardan oluşan bir grup toplanır. Ancak burada karşılaştırılabilir firmaların doğru seçilmesi oldukça önemlidir. Zira emsal firmaların yanlış tespit edilmesi, karşılaştırma yapılan finansal oranların yeknesak olmaması, verilerin alındığı finansal tablolarda gerekli düzeltmelerin yapılmaması, karşılaştırma yapılacak çarpanların doğru bir şekilde tespit edilememesi gibi konuları uygulamada yapılan belli başlı hatalar olarak sıralamak mümkündür (Kulalı ve Bilir, 2013: 155). Ayrıca emsal firmaların olması gerekenden az ya da fazla tespit edilmesi de analizin yanlış sonuçlanmasına neden olacaktır (Kulalı ve Bilir, 2013: 198). Bu nedenlerle karşılaştırılabilir firmalardan oluşan grubun gerçekten karşılaştırılabilir olup olmadığını görmek için, karşılaştırılabilir firmaların faaliyet gelirleri ya da hasılatlarıyla firmaya verilen değer arasındaki korelasyon hesaplanmalıdır. Korelasyon yüksek ve pozitif ise halka açık olmayan şirketle benzer, karşılaştırılabilir firmaların doğru seçildiğini söylemek doğru olacaktır. Ayrıca halka açık olmayan firmanın birden fazla iş kolunda faaliyet gösteriyor olması durumunda, her bir iş kolu için karşılaştırılabilir firmaları ayrı ayrı tespit etmek gerektiği unutulmamalıdır (Damodaran, PCV: 182).

II. İkinci aşamada, birinci aşamada seçilmiş karşılaştırılabilir halka açık şirketlerin beta katsayıları tahmin edilir ve bu beta katsayılarının ortalamaları alınır. Bu betalar kaldıraçlı betalar olduğundan Borç/Özkaynak oranları dikkate alınarak karşılaştırılabilir firmaların kaldıraçsız betaları hesaplanır(Kırlı, 2006: 131). Bunun için aşağıdaki eşitlikten yararlanılır (Damodaran, PCV: 183).

$$
\beta_{u}=\frac{\beta_{l}}{(1+(1-t)(D / E)}
$$

$\mathrm{Bu}$ eşitlikte;

$\beta_{u}=$ Kaldıraçsız betayı, $\beta_{l}=$ Kaldıraçlı betayı,

$t=$ Vergi oranın1,

$\frac{D}{E}=\frac{\text { Borç }}{\ddot{O}_{\text {zsermaye }}}$ oranını ifade etmektedir.

III. Bu aşamada sistematik risk ölçütü beta katsayısının tahmin edilmeye çalışıldığ halka açık olmayan şirketin borç/özsermaye oranı hesaplanır.

IV. Son aşamada, II. aşamada halka açık şirketler için tahmin ortalama kaldıraçsız beta değeri ve III. aşamada hesaplanmış halka açık olmayan şirketin borç/özkaynak oranı veri alınarak, halka açık olmayan şirketin kaldıraçlı betası tahmin edilir. Bunun için aşağıdaki eşitlikten yararlanılır.

$$
\beta_{\text {private }}=\beta_{u}(1+(1-t)(D / E)
$$

Bu eşitlikte; 
$\beta_{\text {private }}=$ Halka açık olmayan şirketin kaldıraçı ı betasını ifade etmektedir.

Karşılaştırılabilir firmalar yardımıyla tahmin edilen kaldıraçlı betalar, hesaplamadaki tarihsel hisse senedi fiyatı ihtiyacını ortadan kaldırarak, regresyon betaları tarafindan oluşturulan standart hatayı azaltmaktadır. Ayrıca her ürün grubu için farklı sermaye maliyeti hesaplandığından, değişen ürün karması sorununu da ortadan kaldırmaktadır (Beneda: 2003: 66). Ayrıca, kaldıraçlı betalar geçmiş dönemin ortalama kaldıracından ziyade firmanın içinde bulunduğu dönemin finansal kaldıracından üretildiği için daha güvenilir bilgi sunduğunu söyleyebiliriz.

\section{LITERATÜR TARAMASI}

Literatür incelendiğinde, piyasa temelli risk ölçütü olan beta katsayısı ile muhasebe temelli değişkenler arasındaki ilişkiyi inceleyen çok sayıda araştırma olduğu görülmektedir. Yapılan araştırmalar, her ne kadar piyasa ve muhasebe betaları arasındaki ilişkinin derecesi açısından farklılık gösterse de bütün araştırma sonuçları, böyle bir ilişkinin var olduğunu vurgulamaktadır.

Beta katsayısı ve muhasebe temelli değişkenler arasındaki ilişkinin incelendiği ilk çalışma, Ball ve Brown (1969) tarafından yapılmıştır. Piyasanın firma riskliliğini algılayabilme derecesinin analiz edildiği söz konusu çalışmada, 1946-1966 döneminde 261 firma üzerinde regresyon analizi uygulanarak, beta katsayısında meydana gelen değişimin, yaklaşık \%35-\%40'lık bir kesitinin muhasebe temelli bir ölçüt olan, karla açıklanabileceği ortaya konmuştur (Almisher ve Kısh, 2000: 24).

Beaver, Kettler ve Scholes (1970), diğer bir ampirik çalışmada, sistematik riski etkileyen değişkenleri tespit etmek amacıyla, toplam 307 adet firmanın 1947-1956 ve 19571965 dönemlerine ait verilerinden faydalanıp, yedi adet muhasebe temelli değişkenin kullanıldığı, daha kapsamlı bir çalışma yapmıştır. Bu değişkenler; kar payı dağıtım oranı, büyüme oranı, finansal kaldıraç oranı, likidite oranı, firmanın büyüklüğü, karlılığın değişkenliği ve muhasebe betasıdır. Çalışma sonucunda, piyasa betalarında meydana gelen değişimleri en iyi açıklayan değişkenlerin kar payı dağıtım oranı, büyüme oranı ve karlılı̆̆ın değişkenliği olduğu tespit edilmiştir. Ayrıca, menkul kıymetler bireysel bazda incelendiğinde, muhasebe ve piyasa betaları arasındaki ilişkinin derecesi, her iki dönem için sırasıyla $\% 44$ ve \%23 olduğu tespit edilmiştir. Portföy bazında incelendiğinde ise bu oranlar, \%68 ve \%46 olmuştur (Beaver vd., 1970: 660-680).

Gonades (1973) benzer bir çalışmada, Ball ve Brown ile Beaver ve diğerlerinin geçerliliğini tespit etmiştir. New York Borsası'ndan rastgele seçilen 99 firmalı bir örnekleme resgresyon analizi uygulayarak, sistematik riskin piyasa temelli ve muhasebe temelli tahminleri arasında düşük düzeyde ama anlamlı bir ilişki bulmuştur. Ball ve Brown ile Beaver vd. çalışmalarında öz sermayenin piyasa değerini kullanırken, Gonades toplam varlıkların defter değerini kullanmıştır. Gonades, kendisinin hesapladığı muhasebe betalarının, daha 
önceki çalışmalarda hesaplanan muhasebe betalarına göre, daha saf ve gerçekçi olduğunu savunmaktadır. Rosenber ve McKibben (1973), aynı yıl 18 adet muhasebe temelli değişken kullanarak yaptıkları çalışmada Gonades'in çalışmasını destekleyici bulgular elde etmişlerdir.

Yukarıda belirtilen çalışmaların sonuçlarındaki farklılıkları gidermeyi amaçlayan, Beaver ve Manegold (1975), piyasa ve muhasebe betaları arasındaki ilişkinin boyutunu, üç farklı biçimde incelemiştir. Buna göre kar rakamı; firmanın öz sermayesinin piyasa değeriyle, öz sermayenin defter değerine bölünmesiyle ve toplam varlıkların yüzdesi olarak alınıp hesaplamalar yapılmıştır. New York Borsası'nda hisseleri işlem gören 254 firmayı kullanarak, tek bir güvenlik seviyesinde, piyasa betasında meydana gelen değişimin yalnızca \%20sinin muhasebe betasında meydana gelen değişimle, açıklanabildiğini tespit etmişlerdir (Almisher ve Kish, 2000: 24).

Castagna ve Matolcsy (1978) 1967-1976 dönemine ait Avusturya borsasında işlem gören 140 firma üzerinde, muhasebe verileri ile özkaynağın sistematik riski arasındaki ilişkiyi ortaya koymak amacıyla, finansal yapı oranları, karlılık oranları ve likidite oranlarını kullanarak analiz yapmışlardır. Finansal yapı oranı olarak borç/özkaynak oranı, borç/toplam kaynak, borç/piyasa değeri alınırken, likidite oranı olarak, likidite oranı ve cari oran alınmış, karlılık oranı olarak da FVÖK/toplam varlık, net kar/öz kaynak, temettü ödemeleri/kar, FVÖK/faiz, hisse başına gelirdeki değişim, varlıkların büyüklügünün logaritması, hisse senetlerinin işlem hacmi alınmıştır. Sonuçta borç/öz kaynak, borç/toplam kaynak, borç/piyasa değeri, FVÖK/toplam varlık, temettü/kar, hisse başına gelirdeki artış, aktif büyüklügünün logaritması ve işlem hacmi ile beta arasındaki ilişki pozitif iken diğer değişkenlerle negatif yönlü ilişki tespit edilmiştir (Tanrıöven ve Aksoy, 2011: 123).

Rosenberg ve Rudd (1987) tarafindan yapılan ve on yıllık bir araştırmanın sonucu olarak ortaya çıkan çalışmada, betada meydana gelen değişimleri açıklayan en önemli muhasebe temelli değişkenlerin büyüme oranı, karlılığın değişkenliği, finansal kaldıraç oranı ve firmanın büyüklüğü olduğu tespit edilmiştir (Ercan, 2007: 299).

İsmail ve Kim (1989), piyasa betaları ile muhasebe betaları arasındaki ilişkiyi dört farklı kar tanımı altında incelemiştir. 1967-1985 döneminde 272 adet firmanın verileriyle 4 kar tanımını da kullanarak muhasebe ve piyasa betaları arasında anlamlı bir ilişki bulmuşlardır. Ayrıca diğer çalışmalarla tutarlı olarak tespit edilen ilişki portföy düzeyinde, bireysel düzeyden daha güçlüdür (Almisher ve Kısh, 2000: 25).

Kulkarni, Powers ve Shannon (1991), muhasebe ve piyasa betaları arasındaki ilişkiye yeni bir boyut kazandırmış, farklı üretim yapma imkanına sahip firmaların alt birimleri için piyasa verileri mevcut olmadığından, o alt birimin iç getiri oranının hesaplanmasında, muhasebe betalarının kullanılabileceğini belirtmiştir. Verinin yetersiz ya da kısıtlı olduğu durumlarda, tahmin hatalarını azaltmak amaciyla, alt birimlerin muhasebe betalarının hesaplanmasında, benzer ürünler üreten birimleri içine alan bir portföy oluşturmuştur. Sonuç 
olarak, muhasebe betalarının piyasa betaları yerine kullanılabilecek, sağlıklı bir alternatif olabileceğini belirtmiştir.

Karels ve Sackley (1993) piyasa betaları ve muhasebe betaları arasındaki ilişkiyi, bankacılık sektöründe incelemek amacıyla 71 adet Birleşik Devletler merkezli bankayı içine alan örneklem kullanmış ve sonuçta muhasebe ve piyasa betaları arasında anlamlı bir ilişki tespit etmiş, ayrıca incelenen dönem uzadıkça ilişkinin kuvvetinin azaldığını belirlemişlerdir.

Berkowitz (1998) tarafından yapılan diğer bir araştırmada ise, 1975-1996 döneminde, Kanada'da faaliyet gösteren halka açık olmayan 144 adet firmanın verileri kullanılarak, geçmiş beta değerlerinin, gelecekteki beta değerlerini etkileme derecesi araştırılmıştır. Çalışmada, finansal kaldıraç oranı, karlılığın değişkenliği, varlıklardaki büyüme oranı ve muhasebe betası değişkenleri açıklayıcı değişkenler olarak kullanılmıştır. Sonuçta, geçmiş verilerin geleceğe yönelik tahminler üzerinde etkisinin, düşük güvenilirlikte olduğu tespit edilmiştir (Ercan vd., 2007: 299).

İMKB'de yapılan bir çalışmada Canan ve Mehmet Eryiğit (2009) 1995-2005 döneminde İMKB'de faaliyet gösteren 72 firmanın temel finansal oranlarının, sistematik risk üzerindeki etkisini incelemek amacıyla, regresyon analizi yapmışlardır. Çalışma sonuçlarına göre, borç/özkaynak oranı ve ROE’nin sistematik risk üzerinde etkisi tespit edilememiş, varlık devir hızı, savunma aralığı ve asit test oranının, sistematik riskle ilgili değişkenler olduğu sonucuna varılmıştır.

\section{HALKA AÇIK OLMAYAN ANONIM ŞİRETLERDE SISTEMATIK RISKK ÖLÇÜTÜ BETA KATSAYISININ TAHMIN EDİLMESI}

\subsection{Araştırmanın Amacı}

Halka açık olmayan şirketlerin; halka ilk arzında, birleşmelerde ve satın almalarda değerinin tespit edilmesi, halka açık olan şirketler kadar kolay olmamaktadır. Bu doğrultuda çalışmada, halka açık olan şirketlerin betaları ile mali tablolarından elde edilen ve literatürde en çok kullanılan temel finansal oranları arasında ilişki kurularak elde edilecek regresyon denklemi yardımıyla aynı sektörde yer alan halka açık olmayan bir şirketin betasının tespit edilmesi amaçlanmaktadır. Tespit edilen bu betalar sayesinde halka açık olmayan şirketin değeri belirlenebilecektir.

\subsection{Araştırmanın Yöntemi ve Kapsamı}

Çalışmada, Borsa İstanbul'da (BİST) 2011 ile 2015 yılları arasında (5 yıl) devamlı olarak işlem gören ve turizm sektöründe yer alan 9 şirketin 3'er aylık bilanço ve gelir tablosu verileri kullanılmıştır.

Çalışmada bağımlı değişken olarak şirketlerin 3'er aylık beta katsayıları kullanılmıştır. Bağımsız değişken olarak ise firmaların bilânço ve gelir tablolarından elde edilen oranlar kullanılmaktadır. Bu oranlar aşağıdaki tabloda verilmektedir. 
Tablo 1: Araştırmada Kullanılan Bağımsız Değişkenler

\begin{tabular}{|l|l|}
\hline 1. Cari Oran & 9. Faiz Karşılama Oranı \\
\hline 2. Asit-Test Oranı & 10. Kar Marjı \\
\hline 3. Nakit Oran & 11. ROA (Aktif Karlılı̆̆ı) \\
\hline 4. Stok Devir Hızı & 12. ROE (Özsermaye Karlılığı) \\
\hline 5. Alacak Devir Hızı & 13. Özsermaye Çarpanı \\
\hline 6. Varlık Devir Hızı & 14. Aktifin Logaritması \\
\hline 7. Toplam Borç Oranı & 15. Satışların Logaritması \\
\hline 8. Uzun Vadeli Borç Oranı & 16. Aktif Büyüme Oranı \\
\hline
\end{tabular}

Araştırmada panel veri analizi yöntemi uygulanmıştır. Panel veri aynı yatay kesit birimlerinin zaman içerisinde tekrarlı gözlemlerinden oluşan veri seti olarak tanımlanabilir (Wooldridge, 2002: 6). Panel veriler zaman ve birim boyutunu dikkate aldığından örneklemdeki gözlem sayısı artmakta, serbestlik derecesini artırmakta ve bağımsız değişkenler arasındaki çoklu doğrusal bağlantıyı azaltmaktadır. Bundan ötürü uygulanacak testlerin gücünde oldukça büyük iyileşmeler görülmekte ve tahminlerin etkinlikleri artmaktadır (Hsiao, 2003:3). Panel verilerle çalışıldığında, her bir birim tüm zamanlar boyunca gözlemlenmişse "dengeli panel”; bazı birimler için bazı zamanlar kayıpsa "dengesiz panel” söz konusu olmaktadır (Tatoğlu, 2016: 5). Bu çalışmada her birim tüm zamanlar boyunca gözlemlendiğinden dengeli panel kullanılmıştır. Zaman serileri ile kesit serilerin bir araya getirilmesiyle oluşturulan panel veri modeli, aşağıdaki eşitlikteki gibi ifade edilmektedir (Güriş).

$$
\begin{aligned}
& Y_{i t}=\beta_{1 i t}+\beta_{2 i t} X_{2 i t}+\ldots+\beta_{k i t} X_{k i t}+\varepsilon_{i t} \\
& \mathrm{i}=1, \ldots, \mathrm{N} \\
& \mathrm{t}=1, \ldots, \mathrm{N}
\end{aligned}
$$

İncelenen örnekte zaman devre sayısı az, birim sayısı çok ise sabit etkili model tercih edilirse serbestlik derecesi sorunu olabilir. Bu nedenle rassal etkili modeller tercih edilebilir. $\mathrm{Bu}$ ve benzeri zorunluluklar ve tercih nedenleri yoksa model tercihi "Hausman Testi" kullanılarak yapılabilir. Sabit etkili modellerde bağımsız değişkenlerin hata terimi bileşenleri ile ilişkisiz olduğu varsayımı yokken, rassal etkili modellerde hata terimi bileşenleri ile modeldeki bağımsız değişkenlerin ilişkisiz olduğu varsayımı vardır. Kısaca rassal etkili modellerde $\mathrm{E}\left(\mathrm{V}_{\mathrm{it}} / \mathrm{X}_{\mathrm{it}}\right)=0$ veya $\mathrm{E}\left(\alpha_{\mathrm{i}} / \mathrm{X}_{\mathrm{it}}\right)=0, \mathrm{E}\left(\lambda_{\mathrm{t}} / \mathrm{X}_{\mathrm{it}}\right)=0$ varsayımlar1 gereklidir. Hausman Testi bu varsayıma dayanarak geliştirilmiştir. Rassal etkili modelin hata teriminde yer alan bileşenler, bağımsız değişkenler ile ilişkiliyse, sabit etkili modelin tahmincileri tutarlı olurken, rassal etkili modelin tahmincileri tutarlı olmayacak ve sabit etkili modelin kullanılması daha uygun olacaktır. Rassal etkili modelin hata teriminde yer alan bileşenler, bağımsız değişkenler ile ilişkisizse, sabit ve rassal etkili modellerin tahmincileri tutarlı olurken, rassal etkili 
modelin tahmincileri asimtotik olarak etkin olacak ve rassal etkili modelin kullanılması daha uygun olacaktır (Güriş, 2015: 37).

Analiz sonuçlarıyla ilgili sağlıklı yorumlar yapılabilmesi için otokorelasyonun yani hata terimleri arasında ilişkinin olmaması gerekir. Breusch-Pagan Langrange Çarpanı Testi ile birimler arası korelasyonsuzluk temel hipotezi sınanmaktadır. Sabit etkili panel veri modellerinde değişen varyans sorununun olup olmadığının incelenmesi amaciyla da Değiştirilmiş Wald Testi geliştirilmiştir (Güriş:2015:72). Modelde heteroskedasite, otokorelasyon veya birimler arası korelasyondan en az biri varsa, ya parametre tahminlerine dokunmadan standart hatalar düzeltilmeli (dirençli standart hatalar elde edilmeli) ya da varlıkları halinde uygun yöntemlerle tahminler yapılmalıdır. Sabit ya da tesadüfi etkiler modelinde heteroskedasiteye karşı dirençli standart hataları elde edebilmek için robust kullanılır (Tatoğlu, 2012: 241).

Araştırmamızda 2011-2015 yılları arasındaki beş yılı kapsayan 3'er aylık dönem verileri esas alınarak, Borsa İstanbul (BİST)'de turizm sektöründe işlem gören işletmeler incelenmiş̧tir. Bu doğrultuda çalışma evrenimizi, sektörde yer alan ve süreklilik arz eden 9 işletme oluşturmaktadır. Bu işletmelerin www.kap.gov.tr. adresinden temin edilen, finansal tablolarından (bilanço ve gelir tablosu) ve dipnotlarından elde edilen veriler Stata 12 paket programı kullanılarak çözümlenmiş̧tir. Bir bütün olarak bakıldığında N (9) x T (20) = NT (180) gözlem söz konusudur. 1 bağımlı ve16 bağımsız değişken olduğu düşünüldüğünde, toplamda 3060 veri analize sokulmuştur.

\subsection{Araştırma Bulguları}

Uygulamada öncelikle panel veri analizi modelinde sabit etki modeli ya da rassal etki modeli yöntemlerinden hangisinin bizim modelimize uygun olduğunun tespit edilmesi gereklidir. Bu amaçla Hausman testi yapılmıştır.

Hausman Testi sonuçlarına göre; Prob $=0.000>0.005$, ki-kare istatistik değeri 85.26 olarak bulunmuş, böylece sabit etkiler modelinin geçerliliği ortaya konmuştur. Daha sonra modelde oto korelasyon problemi olup olmadığını test etmek için Breusch-Pagan Langrange Çarpanı Testi ve Farklı Varyans testlerinden yararlanılmıştır. Breusch-Pagan Langrange Çarpanı Testi sonucunda; Prob $=0.0000<0.05$, ki-kare istatistik değeri 91.058 olduğundan birimler arasında korelasyon olduğu ortaya çıkmıştır. Farklı varyans analizi sonucunda ise Prob $=0.0000<0.005$ olduğundan birimlerin varyanslarının eşit olmadığı tespit edilmiştir. Bu durumda otokorelasyon sorunu ortaya çıkmıştır. Otokorelasyon sorununun olumsuz etkisini ortadan kaldırması amacıyla Robust Tekniği kullanılmıştır.

Buna göre elde edilen sonuçlar Tablo 2.'deki gibidir. 
Tablo 2: Beta ve Finansal Oranlar Modeli

\begin{tabular}{|l|c|c|c|c|}
\hline Beta & Katsayı & Hata & t-istatistik & Anlamlılı \\
\hline Sabit & 1.1673190 & 1.8047660 & 0.65 & 0.536 \\
\hline Cari Oran (CO) & 0.0139018 & 0.0046004 & 3.02 & $0.017^{*}$ \\
\hline Asit-Test Oranı (ATO) & -0.0068843 & 0.0161797 & -0.43 & 0.682 \\
\hline Nakit Oranı (NO) & 0.00869929 & 0.0128697 & 0.68 & 0.518 \\
\hline Stok Devir Hızı (SDH) & 0.0014733 & 0.0030089 & 0.49 & 0.638 \\
\hline Alacak Devir Hızı (ADH) & 0.0001758 & 0.0005439 & 0.32 & 0.755 \\
\hline Varlık Devir Hızı (VDH) & -0.8698979 & 0.4205180 & -2.07 & 0.072 \\
\hline Toplam Borç Oranı (TBO) & 0.6010700 & 0.4149163 & 1.45 & 0.185 \\
\hline Uzun Vadeli Borç Oranı (UVBO) & 0.0562359 & 0.2637000 & 0.21 & 0.836 \\
\hline Faiz Karşılama Oranı (FKO) & 0.0000618 & 0.0000213 & 2.90 & $0.020^{*}$ \\
\hline Kar Marjı (KM) & -0.0020040 & 0.0007650 & -2.62 & $0.031^{*}$ \\
\hline ROA & 1.2091590 & 0.4784202 & 2.53 & $0.035^{*}$ \\
\hline ROE & -0.0008340 & 0.0048242 & -0.17 & 0.867 \\
\hline Özsermaye Çarpanı (ÖÇ) & 0.0017426 & 0.0009600 & 1.82 & 0.107 \\
\hline Aktifin Logaritması (LogA) & -0.1322207 & 0.2149869 & -0.62 & 0.556 \\
\hline Satışların Logaritması (LogS) & 0.0560616 & 0.0132357 & 4.24 & $0.003^{*}$ \\
\hline Aktif Büyüme Oranı (ABO) & -0.0082331 & 1.804766 & 0.65 & 0.536 \\
\hline Anlamlılık: 0.000 & & & & \\
\hline Not* 0,005 dizeyinde anlat & & \\
\hline
\end{tabular}

Not:* 0,005 düzeyinde anlamlı olan değişkenler

Buna göre, işletmelerin cari oranındaki 1 birimlik değişim betasında aynı yönde 0.0139018 birimlik, faiz karşılama oranındaki 1 birimlik değişim betasında aynı yönde 0.0000618 birimlik, kar marjındaki 1 birimlik değişim betasında negatif yönde 0.0020040 birimlik, ROA'daki bir birimlik değişim betasında aynı yönde 1.2091590 birimlik, aktif büyüme oranındaki 1 birimlik değişim betasında negatif yönde 0.0082331 birimlik bir değişime neden olmaktadır. Yukarıdaki modelde yer almasına rağmen Asit-Test Oranının (Anlamlılık: 0.682), Nakit Oranın (Anlamlılı: 0.518), Stok Devir Hızının (Anlamlılık: 0.638), Alacak Devir Hızının (Anlamlılık: 0.755), Varlık Devir Hızının (Anlamlılık: 0.072), Toplam Borç Oranının (Anlamlılık: 0.185), Uzun Vadeli Borç Oranının (Anlamlılık: 0.836), ROE'nin (Anlamlılı: 0.867), Özsermaye Çarpanının (Anlamlılı: 0.107), Aktifin Logaritmasının (Anlamlılık: 0.556) ve Aktif Büyüme Oranının (Anlamlılık: 0.536) beta katsayısı üzerinde anlamlı bir etkisinin olmadığı görülmektedir.

Ancak modele göre bir tahmin yapacak olmamız sebebiyle ve hatalı sonuç elde etmemek adına modelde anlamsız çıkan ve aralarında çoklu doğrusal bağlantı olan oranlar $p$ 
değerlerinin büyüklüğüne göre en büyük olandan başlanarak tek tek çıkarılarak robust teknikle tekrar tekrar model kurulmuştur. Ortaya çıkan nihai model aşağıdaki gibidir.

Tablo 3: Nihai Model Sonuçları

\begin{tabular}{|l|c|c|c|c|}
\hline Beta & Katsayı & Hata & t-istatistik & Anlamlı.ık \\
\hline Sabit & 0.1770301 & 0.0730113 & 2.42 & 0.042 \\
\hline Cari Oran (CO) & 0.0113901 & 0.0043029 & 2.65 & 0.029 \\
\hline Toplam Borç Oranı (TBO) & 0.5225223 & 0.1367935 & 3.82 & 0.005 \\
\hline Faiz Karşılama Oranı (FKO) & 0.0000809 & $7.96 e-06$ & 10.16 & 0.000 \\
\hline Kar Marjı (KM) & -0.0016236 & 0.0005261 & -3.09 & 0.015 \\
\hline Satı̧̧ların Logaritması (LogS) & 0.0459035 & 0.0111107 & 4.13 & 0.003 \\
\hline F Değeri: 69.17 & & & \\
\hline Anlamlılık: 0.000 &
\end{tabular}

Yapılan tüm bu analiz sonuçlarına bakıldığında, modellerimizin bir bütün olarak anlamlı olduğu tespit edilmiştir. Bu sonuçlar ışığında beta modelimiz aşağıdaki gibidir:

Beta $=0.1770301+0.0113901 \mathrm{CO}+0.5225223 \mathrm{TBO}+0.0000809 \mathrm{FKO}-$ $0.0016236 \mathrm{KM}+0.0459035 \operatorname{LogS}$

Halka Açık Olmayan “ $X$ ” İşletmesinin Betası = 0.1770301 + 0.0113901(0.868) + $0.5225223(0.347)+0.0000809(0.682)-0.0016236(-0,102)+0.0459035(6.720)=$ 0.676924246

Eğer bir hissenin betası 1 ise, endeksin \%10 arttığ bir dönemde o hissenin \%10 değer kazanması, endeksin \%10 düştüğü bir dönemde ise o hissenin \%10 düşmesi beklenir. Bu durumda, halka açık olmayan şirketin betası 0.676 ise endeksin \%10 yükseldiği bir dönemde o hissenin \%6.76 yükselmesi, endeksin \%10 düştüğü bir dönemde ise, o hissenin \%6.76 düşmesi beklenir.

Modelin halka açık olmayan " $X$ " işletmesinin verileriyle kurulması sonucunda elde edilen beta (0.637) bize işletmenin 2015 yılının betasını vermektedir. Eğer " $X$ " işletmesinin 2015 yılı finansal tablo verilerinden yola çıkarak 2016 yılının betasını tahmin etmek istersek, halka açık olan işletmelerin bağımsız değişkenlerinin bağımlı değişken olan beta üzerindeki 1 y1l gecikmeli etkisiyle yeniden panel veri analizi yapılarak yeni bir model kurmak gerekecektir. Böylelikle halka açık olmayan işletmenin bağımsız değişkenleri modele yerleştirilerek bir sonraki yılın betası (riski) tahmin edilebilecektir. Bir sonraki çalışmada modelin gecikmeli uygulaması yapılacaktır. 


\section{SONUÇ}

Halka açık olmayan şirketlerin sistematik riskinin tahmin edilmesi, yatırımcılar açısından en az halka açık şirketler kadar önemlidir. Halka açık olmayan bir firmanın ilk halka arzı veya borsada işlem görmeyen şirketlerin satın alma ya da birleşme işlemlerinde betanın bilinmesi yatırım kararının daha gerçekçi irdelenmesini sağlayacaktır. Örneğin, bir menkul kıymet yatırımcı açısından bir getiri ifade ederken; çıkaran şirket açısından da özkaynak maliyeti içermektedir. Gerek yatırımcıların menkul kıymetlere yatırım yaparken risk ve getiri arasında ilişki kurması, gerekse de şirketlerin sermaye maliyeti hesaplamalarında özkaynak maliyetinin bilinmesi gereği, menkul kıymetlere ait risklerin doğru bir şekilde ölçülmesini gerektirmektedir. Aynı şekilde satın alma ve birleşme işlemlerinde de işletmenin gerçek değerinin hesaplanması açısından betanın bilinmesi oldukça önemlidir.

Halka açık olmayan şirketler için piyasada oluşan fiyat bilgileri mevcut olmadığından, sistematik risk ölçütü beta katsayılarının hesaplanmasında zorlukla karşılaşılmaktadır. Bu nedenle çalışmada, halka açık olan şirketlerin betalarından ve finansal tablolardan elde edilen rasyolarından hareket ederek, halka açık firmaların betaları ile rasyoları arasında anlamlı bir ilişki olup olmadığı incelenmiştir. BİST Turizm Sektöründe Stata 12 paket programı yardımıyla yapılan panel veri analizi sonucunda beta katsayısı ile şirketlerin hesaplanmış olan rasyolarından 5 tanesi arasında anlamlı bir ilişki bulunarak betaya ilişkin bir model kurulmuştur. Kurulan bu model, aynı sektörde yer alan ve benzer büyüklükteki halka açık olmayan şirketin finansal tablolarından elde edilen verileriyle çalıştırılarak halka açık olmayan şirketin betası tahmin edilebilmiştir. Böylece şirket tahmini beta yardımıyla gerçek değerini hesaplayabilecek ve halka açılma, birleşme ya da satın alma sürecinde daha rasyonel kararlar verilebilecektir.

Çalışma, literatürde yer alan diğer çalışmalarla benzerlik göstermekte olup, elde edilen modelin halka açık olmayan gerçek bir işletmeye ${ }^{1}$ uygulanması yoluyla diğer çalışmalardan farkını ortaya koymaktadır. Ancak beta modelinin farklı sektörlerde yer alan şirketlerde uygulanabilmesi için farklı finansal oranlar yardımıyla değişik sektörlere uyum sağlayacak şekilde geliştirilmesi daha uygun olacaktır.

\section{KAYNAKLAR}

Almisher, Mohamad A.- Kish, Richard J. (2000), “Accounting Betas - An Ex Anti Proxy For Risk Within The IPO Market", Journal of Financial and Strategic Decisions, Volume: 13, Number: 3.

Beaver, William - Kettler, Paul - Scholes, Myron, (1970) "The Association Between Market Determined and Accounting Determined Risk Measures", The Accounting Review, Volume: 45.

\footnotetext{
${ }^{1}$ Turizm sektöründe yer alan gerçek bir işletmeden, sadece çalışmada kullanılmak üzere finansal tabloları alınmıştır.
} 
Beneda, Nancy L. (2003), "Estimating Cost of Capital Using Bottom-up Betas", The CPA Journal, Number: 73.

Damodaran, Aswath (2002), Investment Valuation: Tools and Techniques for Determining the Value of Any Asset, John Wiley \& Sons, Inc., New York.

Damodaran, Aswath, Private Company Valuation, p. 182. http://people.stern.nyu.edu/adamodar/pdfiles/eqnotes/pvt.pdf, Erişim Tarihi: 30.01.2015.

Elton, Edwin J. - Gruber, Martin J. - Brown, Stephen J. - Goetzmann, William N. (2014), Modern Portfolio Theory and Investment Analysis, Ninth Edition, John Wiley \& Sons, New York.

Ercan, M. Kamil - Öztürk, M. Başaran vd. (2007), "Halka Açık Firmaların Beta Katsayılarının Regresyon Modeli İle Tespiti ve Halka Açık Olmayan Firmalara Yönelik Uygulanabilirliği”, Dokuz Eylül Üniversitesi İktisadi ve İdari Bilimler Fakültesi Dergisi, Cilt: 22, Sayı: 2.

Ersoy, Ayten - Boncuk, Aslihan E. - Suntur, Natur (2010), "Beta Katsayısının Muhasebe Verilerine Dayalı Risk Ölçütleriyle İlişkilendirilmesi: İMKB Örneği”, Muhasebe Ve Finansman Dergisi, Sayı: 45.

EryiĞit, Canan - Eryiğit, Mehmet (2009), "Temel Finansal Oranların Sistematik Riske Etkisi." İktisat İşletme ve Finans, Cilt: 24, Sayı: 281.

FINNET, https://www.finnet.com.tr/yardim/risk.asp? $S C=Y$, (Erişim Tarihi: 09.03.2017)

Güriş, Selahattin (2015), Stata İle Panel Veri Modelleri, Der Yayınları, İstanbul.

HSİAO, Cheng (2003), Analysis of Panel Data, 2nd Edition, Cambridge University Press, Cambridge.

Karels, Gordon V. - William H. Sackley (1993), "The Relationship Between Market and Accounting Betas for Commercial Banks." Review of Financial Economics, Volume: 2, Number: 2.

Kırlı, Mustafa (2006), "Halka Açık Olmayan Şirketlerde Sistematik Risk Ölçütü Beta Katsayısının Tahmin Edilmesi”, Yönetim ve Ekonomi, Dergisi, Cilt: 13, Sayı: 1.

Kulalı, İhsan - Bilir, Hakan (2013), "Finansal Çarpanlara Dayalı Değerlemenin Temel Esasları”, Akdeniz İ.İ.B.F. Dergisi, Sayı: 27.

Kulkarni, Mukund S. - Powers, Marian - Shannon, Donald S. (1991), "The Use of Segment Earnings Betas in the Formation of Divisional Hurdle Rates" Journal of Business Finance \& Accounting, Volume: 18, Number: 4.

Rosenberg, Barr - Guy, James (1976), "Prediction of Beta from Investment Fundamentals: Part One", Financial Analysts Journal, Volume: 32, Number: 3.

Tanrı̈ven, Cihan - Aksoy, E. Ebru (2011), “Sistematik Riskin Belirleyicileri: İMKB'de Sektörel Karşılaştırma”, Muhasebe ve Finansman Dergisi, Sayı: 51. 
Tataoğlu Yeldeğen, Ferda (2016), Panel Veri Ekonometrisi, Beta Yayınları, 3. Bask1, İstanbul.

Wooldridge, Jeffrey M. (2002), Econometric Analysis of Cross Section and Panel Data, The MIT Press, Cambridge. 